\title{
4 Business perspective on offshoring of white-collar jobs
}

\subsection{Motives of offshoring of advanced business services}

Multinational enterprises are economic organisations characterised by the high level of efficiency. These units were first to introduce various solutions increasing productivity (such as production lines, containers, or just-in-time manufacturing). MNEs were also directly associated with the development of offshoring of production activities to less advanced economies. These processes profoundly influenced both the operations of the largest corporations and the structure of the entire global economy.

There was one type of operations relatively resistant to the international division of work. These were services provided by the headquarters such as human resource management, research and development or accounting. They were highly embedded into operations of the central office, thus top managers preferred to use the services as tools of control over core operations dispersed globally. Moreover, the potential cost savings were not significant, as those services have only been auxiliary activities and their share in total costs of MNEs have been rather negligent. Anyway, due to advances in the communication technology, standardisation and codification of knowledge, services of headquarters became traded across borders.

Motives of establishing a centre providing headquarters' services can be divided into two groups: expansion and consolidation. However, they may not be idiosyncratic and frequently occur simultaneously. A firm may decide to consolidate its operations in a single foreign ABS unit placed in a location with lower salaries in order to decrease operational costs. But at the same time, the newly established structures may be used to acquire new talents and expand operations into new segments of the market or new foreign markets. For example, a Dutch company decided to establish a centralised ABS unit in Poland as a result of efforts to consolidate its white-collar operations previously spread across Europe. At the same time the company used the unit to expand into new markets and to modify its business model in order to get involved into e-commerce.

Both operational and strategic performance of offshoring were confirmed to be positively affected by low costs and resources availability, however the existence of local networks negatively impacted operational performance of offshore outsourcing operations (Caniato, Elia, Luzzini, Piscitello, \& Ronchi, 2015). It may be explained by the fact that operational performance is expressed in monetary terms, but strategic performance comprehend more sophisticated elements.

In most cases, even if the cost-saving motives are crucial in the beginning, it evolves over time into building competitive advantages (Tate, Ellram, Bals, \& Hartmann, 2009). The offshoring is also a way of strategic learning and business development (Jensen, 2009). His study also confirms that the initial objectives of 
offshoring change over time and as the relationship between home and host firms matures, new opportunities may be derived from the partnership. It means that offshoring of ABS due to its knowledge components may be used to higher extent as a tool of business development, not only a method of costs' reduction. Such a conclusion has an extensive implications for both host and home economies. The earlier attention was that offshoring may reduce employment in home economies, however it may be also used as a competitive advantage for home country firms. Moreover, it is also important from the perspective of incentive policies of host countries, as the offshoring of ABS is rather about skills and talents, not only costs.

Knowledge gains are not exclusively related to ABS, as they can be also observed in less knowledge-intensive services or manufacturing. Anyway, the ABS are designated to add knowledge to the organisation. The potential gains depend on the design of the offshoring process. The baseline approach is that there is an initial transfer of knowledge from an onshore company to an offshore unit to build its initial capacity. Afterwards, the new knowledge is created at the offshore company. To strengthen the process of transferring knowledge from the onshore to an offshore company, it is recommended to build informal links between staff in the units and improve interactions between them (Chen, McQueen, \& Sun, 2013).

There is also the issue of economies of scale. It is important both for captive offshoring and offshore outsourcing arrangements. It means that some operations require a scale that can be provided from abroad. This is important in the context of the newest technologies like AI or ML, which require vast financial and organisation investments.

Researchers distinguish between effects derived from offshore outsourcing and captive offshoring. Due to the fact that outsourcing means employing external expertise, the expected effects can be greater. There may be also value creation by improving management of internal and external resources with respect to changes in the external environment (Mukherjee, Gaur, \& Datta, 2013). Thanks to the flexibility of outsourcing solutions, a company can better adapt to changing demand for its products and services. However, there is also a danger of the erosion of internal resources over a longer period of time. It is especially important when we analyse the competitive advantage, which should be derived from unique resources controlled by a firm, not purchased on open markets (Barney, 1991).

The offshore outsourcing of ABS is more complex than manufacturing outsourcing (Ellram, Tate, \& Billington, 2008). It is predominantly linked to the knowledge element of the process. It also requires more human interactions, what includes elements of cultural distance and personalities of partners. However surprising, the cultural element was not confirmed as important for the performance of offshoring operations (Caniato, Elia, Luzzini, Piscitello, \& Ronchi, 2015). Therefore, the array of motivations is much broader and includes many indirect effects. According to Tate, Ellram, Bals, and Hartmann (2009) there are following gains of offshore outsourcing identified using case study approach: 
- cultural aspects,

- reduction of risk,

- entry into new markets,

- increase of market share,

- increased reputation,

- access to resources,

- process improvements.

International outsourcing of knowledge-intensive process is complex and management should be ready to tackle many pitfalls (Luo, Zheng, \& Jayaraman, 2010). They argue that the key to successful operation is proper integration of outsourced processes into the structure of a company.

From the managerial perspective, the decision about engagement in offshoring irrespective of its mode, is predominantly based on the attitude of the decisionmakers, available resources and experience of the organisation (Pla-Barber, Linares, \& Ghauri, 2019).

The business perspective adds to the policy implications of ABS operations in host economies. Onshore businesses must transfer knowledge to their offshore units in order to make them effective. The transfer takes a form of interactions between employees in the onshore and offshore units. In fact, it may be a transfer of knowledge between home and host economy. Even though there are claims that the transfer is limited. It is in principle against the main goals of offshoring and headquarters should boost it instead of curbing it.

An issue related to offshore outsourcing is "knowledge at risk", which means that a company offshoring knowledge intensive processes can be affected by the loss of knowledge or suboptimal performance of the offshoring arrangement (Williams \& Durst, 2018). It is crucial as knowledge and its flawless use are core competencies of MNEs.

Despite the complexity of offshoring of ABS, the decision-makers do not always employ a rational approach to the international configuration of processes. Some companies decide to use offshoring of ABS because of the "herd behaviour" or "bandwagon effect” (Agrawal, Agrawal, Taylor, \& Seshadri, 2019). It means that managers in a parent company fear of losing competitive advantage or distance to competitors, who have already started offshoring of some operations. It is a kind of peer pressure, also increased by the supervisors or investors. This is especially the case for large multinational firms operating in oligopolistic industries. No surprise that frequently used indicator for relevance of offshoring is the Fortune 500 ranking of companies. At the moment it would be difficult to mention any of the large firms that has not been involved in the offshoring of physical goods or business services.

The offshore outsourcing of advanced services may positively influence building the resources of onshore firms. This is determined by: commitment, trust building, 
knowledge building, and the interconnectedness of resources between onshore and offshore firms (Jensen, 2012).

After taking the decision to offshore processes. it is required to reconsider the organisation of a firm. It is especially important when the number of offshored processes and their complexity increases. Jensen, Larsen and Pedersen (2013) propose three stages in the process of redesigning the organisation: disintegration, relocation and reintegration. All these result in a profound transformation of business processes within a firm. The decision about offshoring, despite frequent internal resistance, should be used as an opportunity to improve operations of the entire organisation. Therefore, the approach of "cut" onshore and "paste" offshore, should be replaced with "extract" onshore, "transform" cooperatively, and "implement" offshore.

\subsection{Modes of delivery of advanced business services}

Offshoring and outsourcing have been treated similarly in the literature. However, from the economic and business points of view they bring different implications. The evidence from business confirms that different approaches to their roles should be applied. Rottman and Lacity (2004) identified twenty good practices for outsourcing and offshoring and found that half of the number was more important for offshoring, five were applicable only to offshoring and five were good both for outsourcing and offshoring. It means that approaches to outsourcing and offshoring should be specifically designed to a particular mode. Also the results may differ as a firm opting for outsourcing to a provider in the same economy cannot gain from the costs differences, which are present in the case of offshoring to lower-cost economy (Weber, 2004). However offshoring brings many additional risks that should be taken into consideration in the final calculation.

To fully understand the phenomenon of foreign firms in ABS is necessary to investigate modes of FDI. There are two basic modes of FDI: a greenfield investment and cross-border merger and acquisition. From the perspective of an enterprise, this is the decision whether to build or buy. In most cases, the companies opt for building a new company abroad from the scratch. There are many arguments for such a decision. In a greenfield project the size and outline of the foreign unit is upon decision of the firm. Moreover, the motivations towards FDI in ABS are different than in market oriented projects. When it comes to ABS, the main motivations are cost cutting and access to talent pools. FDI in ABS does not take into consideration the acquisition of a strong brand or technology. Moreover, this is not the market game to buy potential competitors.

From the perspective of a contact with an end user the ABS can be divided into:

- Front-office processing (e.g. customer service)

- Middle-office processing (e.g. controlling, information risk management, compliance)

- Back-office processing (e.g. accounting, HR). 
We can notice the tendency towards more middle and front functions, once ABS units proved that they are capable of executing back-office functions. The evolution towards more sophisticated operations requires a more complex approach to offshoring, than it was in the case of offshoring of the very mundane tasks. "Back offices collect, manage, and process information as an intermediate input to the production of goods and services" (Wilson, 1995). Actually, ABS with their higher knowledge content do not fit the basic office tasks, but should be rather associated with middle-office processing.

The previously presented distinction between captive offshoring and offshore outsourcing does not fulfil the topic of business strategies towards ABS. The definition of advanced business services can be best illustrated by the analysis of business functions executed at service units (Figure 4).

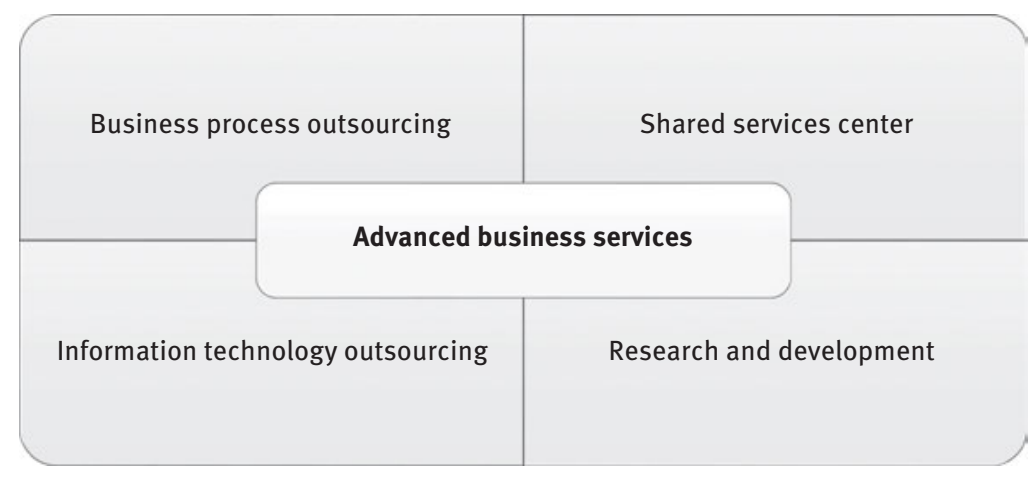

Figure 4: Scope of advanced business services (source: own elaboration).

Two dominant types of units are business process outsourcing (BPO) facilities and shared services centres (SSC). They represent delegating tasks to either an external provider or an internal specialised unit. The choice between the internal and external offshoring depends on the attitudes of the decision-makers in an organisation. If they are focused on decreasing the costs of operations, access to resources or imitation then the external offshoring is what they opt for, however if their main aim is to improve competitiveness, they opt for internal offshoring arrangements (Pla-Barber, Linares, \& Ghauri, 2019).

Moreover, it may be also assumed that the operations within internal offshoring are more firms-specific, not very commoditised. Again, the offshore outsourcing is a preferred option for cost-cutting operations, while market-seeking firms should choose captive offshoring as optimal arrangement for their knowledge-intensive activities (Paz-Aparicio, Muñoz-Bullón, Sanchez-Bueno, \& Ricart, 2018). ABS are considered as requiring more integration between the provider of services and their clients, thus the preferred option should be captive offshoring. It is in line with fact that the complexity of offshore services has been increasing. The decision of companies to use captive 
form in this respect can be linked to the transaction costs of buying services from an external vendor. This is also one of the unique features of service offshoring in comparison to manufacturing offshoring, where such a dilemma is not existent. The captive offshoring and offshore outsourcing should be perceived as the unbundling of corporate functions or vertical disintegration, which means that the "cut and paste" approach does not explain fully the motivations of firms towards new forms of provision of services (Sako, 2006). It can be also interpreted as a method of reorganisation of an enterprise and adjusting its operations to the changing market environment. Such findings are important not only for the strategic operations of the firm, but have also economic implications for home and host economies. It is expected that the internal offshoring can be treated as a longer term arrangement, as it is rather motivated by strategic, not tactical approach.

The particular types of ABS are meant to be executed internationally, not within one economy. Such comment is necessary as outsourcing of business services is frequently delivered to other firms in the same economy. It is even the case for India, where the share of sales of the ABS industry to local partners is rising in recent years.

When discussing the mode of arrangements in offshoring, a hybrid solution of concurrent offshoring has to be introduced. The hybrid solution means combining key characteristics of offshore outsourcing (buy) and captive offshoring (make). However, it is argued that this solution should not be located in-between the internal and external arrangement, but rather as a next step in offshoring arrangement of organisations competent to take advantage of executing some processes within the boundaries of an organisation and some outside it (Jensen \& Petersen, 2013).

There is also another hybrid approach to delivery of ABS. The build-operationtransfer (BOT) "provides an opportunity to leverage the unique talent of a thirdparty provider to establish offshore operations and then transfer the operations to full control of the customer company after a specified time frame" (Youngdahl, Ramaswamy, \& Verma, 2008). Such arrangements are important for operations requiring a high level of expertise and knowledge. This process can be seen as opposite to outsourcing, because it internalises the operations executed in a separate unit outside the boundaries of a firm.

Such a model provides not only an operating unit, but also training and transfer of knowledge to the client's company. The solution can be also cost efficient as its establishment has been delegated to an experienced partner, what saves time and money. The advantages of employing a contract partner to build such a unit are especially visible in foreign markets, where the clients firm lacks the experience, especially with respect to recruitment, but also faces various legal or cultural barriers (Jensen \& Petersen, 2013). The model has been recently applied by firms in services offshoring, whilst its origin are from construction and engineering (Orzes, Sartor, Nassimbeni, \& Fratocchi, 2017).

Figure 5 presents the evolution of the structures of many multinationals. The overall trend is to slim down the organisations, by centralising business processes 


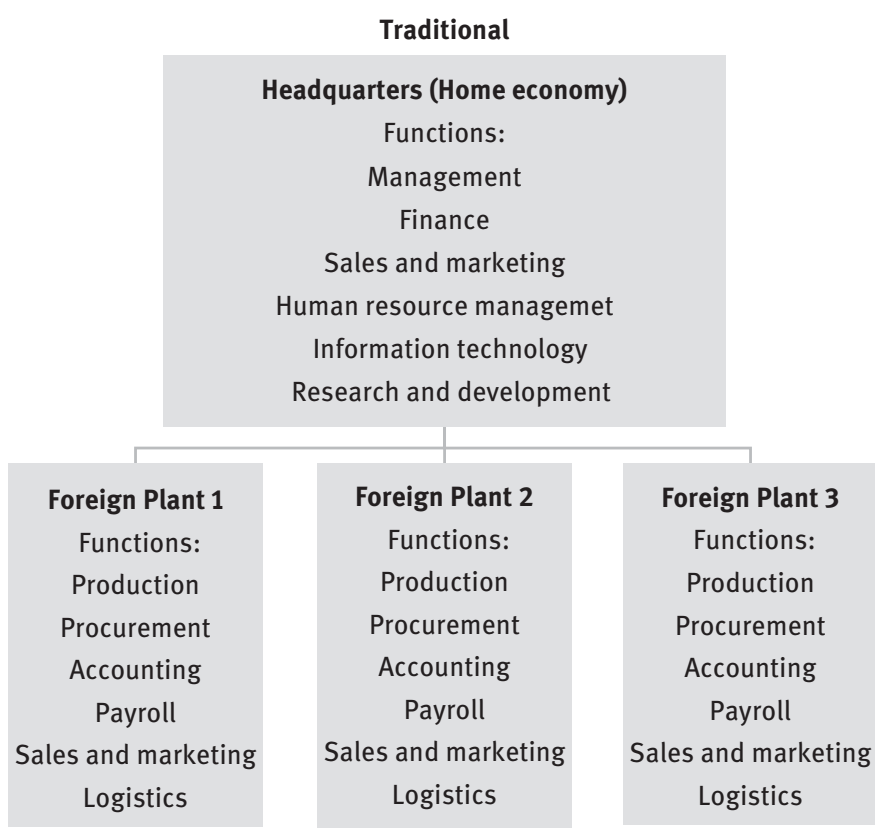

Modern - including advanced business services unit

Headquarters (Home economy)

Functions:

Management

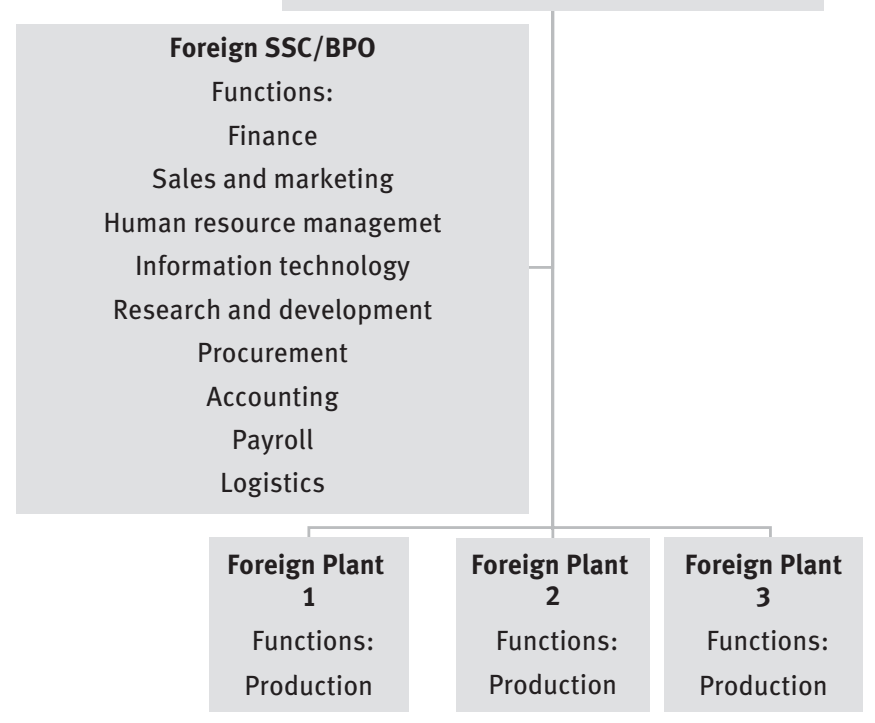

Figure 5: Structure of multinational corporation (source: own elaboration). 
in a specialised unit. This goes much further than building a SSC to perform noncore processes. Thanks to developments in technology and organisation, but also rising maturity of the ABS units, they can also apprehend many core processes, such as sales management or strategic procurement.

However, the transfer of business activities between units of a MNE has international implications. This is an unprecedented transfer of knowledge, but indirectly also power within the organisations. It is because it is more than just supporting functions. Indeed, further development of the model of SSC may mean that very core processes are executed away from the headquarters. In such a situation there is a threat of losing the core competences by the headquarters, but also by the entire organisation in the case of contracting out.

The ABS units within MNEs can be also named service factories. These are units specialised in efficient delivery of business services. In this approach, the SSC/BPO unit should be placed on the same level of the company's structure as manufacturing units. This could also have managerial implications. However, such simplistic view on SSC/BPO reduces the knowledge content of their work.

\subsection{Shared services centres}

The crucial type of service provision arrangements in offshoring are shared services centres. It means moving non-core activities to a separate specialised unit, but still within the boundaries of an organisation. "Shared services generally refers to the centralization of back-office services within a firm to a single location. The geographically dispersed units of a service firm then 'share' the services of a central facility rather than have all the services provided locally” (Metters \& Veerma, 2008, p. 6). The functions that are commonly executed within SSC are: finance (89\%), human resources (63\%) and information technology (53\%) (Deloitte, 2019, p. 7). Shared services do not have to be located in another country with respect to the headquarters, however this is frequently the case and we focus on such arrangements in this book.

Other definitions do not provide an explicit description of shared services, but rather underline some approaches to executing the back-office services. One of them is treating the shared services as "internal customer service" (Soalheira \& Timbrell, 2014). This definition stems from dividing customers of an organisation into external and internal. Treating internal units as customers requires a focus on quality of services and customers' satisfaction. SSCs are also described as "internal outsourcing” (Aksin \& Masini, 2008). It means that functions are taken from particular business units and placed in an organisationally separate unit.

The traditional approach to shared services has been based on three most frequently used terms "centralization", "transaction(s)" and "cost saving” (Soalheira \& Timbrell, 2014). Five main motives of establishing SSC has been identified by Yusof et al. (2016): 
- Cost saving,

- Increasing service performance,

- Reducing redundancy,

- Improving organisation learning,

- Focusing on core business.

According to other studies, the main motives of establishing shared services were cost arbitrage, labour quality, regulatory understanding, and proximity to headquarters (Deloitte, 2019). Therefore the top locations for SSC were in descending order: India, United States, Poland, Costa Rica and Mexico. The arguments are still valid today when it comes to placing SSCs within organisations. However, if the main element of building SSC is to reduce costs, it puts in jeopardy all efforts to build such a unit. Cost saving might be easier achieved by outsourcing. Therefore it is crucial for modern SSCs to pronounce their strategic role within an organisation.

The trend of establishing SSCs is especially visible among large enterprises. More than three quarters of Fortune 500 firms already operate using the SSC model (Richter \& Brühl, 2017). The expected gains from organising services as shared services, lead many firms to apply such an organisational change. A very early example of SSC is the unit established by General Electric in 1985 (Metters \& Veerma, 2008).

The SSC model is not homogenous. There are several approaches to establishing SSC within an organisation. Aksin and Masini (2008) propose four configuration of units depending on the needs and characteristics of the corporation:

- Business-minded optimisers - optimal for medium and large enterprises with streamlined processes,

- Cost watchers - optimal for enterprises focused on low costs of operating a SSC

- Focused adapters - optimal for small enterprises with many processes not supported by integrated information systems, however the quality of services is crucial,

- Immature service providers - optimal for enterprises highly committed to SSC by vast investment and aimed at providing services also to external clients.

Depending on the levels of consolidation and external service receivers, Ulbrich and Borman (2012) distinct four trajectories of SSC:

- Centralised service centre,

- Outsourced shared services,

- Collaborative shared services,

- Decentralised shared services.

The first and second type of the centres in the list above are results of the excessive process standardisation, while the next one is a result of low process standardisation. The collaborative type provides balanced standardisation of services. However, each of the trajectories are associated with some risks that may harm the original aims of establishing the unit. 
Creating a functional SSC requires a strategic approach to service transformation in the areas of simplification, standardisation, consolidation, outsourcing, and insourcing (Akkiraju, Nayak, \& Goodwin, 2009). These elements of the decision making process should be taken at the proper time and to an appropriate extent. It also means that there might be an evolution of the approaches. For example, in the beginning of the transformation a company chooses insourcing to proceed to outsourcing after some years. The approach to SSC should be a part of an overall corporate strategy and should also take into consideration external factors, like the technology change. There is a dynamic evolution of the role of SSC within multinational corporations. "SSC organizations are and will increasingly become more global, complex, and digital, as they seek to provide nimble and efficient services, stronger customer service, and highimpact business outcomes" (Deloitte, 2019, p. 2).

The common point regarding SSC is that, even in a captive form of operations, they are treated in subordination to other operations. The bargaining power of SSC units is lower as they are frequently treated as merely solutions to cut costs. Indeed, the changing nature of a SSC from being on the periphery of an organisation into the strategic role also altered its business model to become more modular, codified, and contractual (Mezihorak, 2018). This is related to the increased control of employees in a SSC, but also decreasing the complexity of activities by dividing them into smaller tasks. However, such an approach to a SSC may limit its inputs into the transformation of the core operations of MNEs and at the same increase the possibility to externalise (outsource) process executed in SSC.

In this vain, SSCs have been created as a result of a hybrid approach to the practise and expertise, with end-to-end processes cutting across particular roles, departments and functions (Herbert \& Seal, 2012). It means that SSCs should be aimed at working with organisation-wide issues and employ best practises in various areas. Such an approach means that a SSC should play central role in the management of the organisation. However, it is rarely postulated that SSCs should go beyond the traditional role of providing back-office services.

The geographic scope of operations of service units underlines the distinction between regional and global service centres. Depending on the core structure of the organisation and geographical diversification of processes, the headquarters may decide to establish one or several units providing services. However, they are never numerous within an organisation.

The choice is rarely for one particular location of offshoring, but rather an array of locations fulfilling business objectives. For example, a British firm located their offshore operations in four destinations, each having a distinctive role to play. SSC in Malaysia (Kuala Lumpur) has been designed to serve operations in East Asia. It is also linked to the language skills and employees there speak main Asian languages. Operations in Poland (Wroclaw) have been mostly focused on EMEA region, sharing similar time zone to the headquarters as an additional asset of the location. The unit in Costa Rica (close to San José) is aimed at supporting operations in Americas. 
The last unit in India (Pune) is a back-office to support operations of all other SSCs. It also requires the organisation of the unit as a 24/7 operations.

It is in line with the "follow-the-sun" benefits, which arise when processes are executed constantly within the organisation, what provides customer service or shortens the time of development on new product or service (Lewin \& Peeters, 2006).

Regional units are organised into a global network with activities in the key offshore locations. There are frequently three such units in:

- Americas

- Europe Middle East and Africa (EMEA)

- Asia, Pacific, Australia and Oceania (APAC).

SSCs share many characteristics with BPO. However, the most important distinction is the level of control over activities taking place within a particular type of service. SSC is a default mode for many companies that are willing or are obliged to keep control over processes and data. This is particularly the case for financial institutions dealing with a lot of regulations towards the secrecy and compliance.

The model of shared services has not only been applied by business enterprises. There is a growing trend among public institutions to implement centralised operation models. The motives of establishing a public SSC are pretty similar to those in the private sector, however not all objectives can easily be met, especially when the public institutions have less possibilities for cost reduction (Tammel, 2017). Therefore if the cost reduction is difficult to achieve, the shared services in the public sector focus on quality and consistency of services, improvement of service delivery, internal exchange of knowledge and access to external skills (Paagman, Tate, Furtmueller, \& de Bloom, 2015). This confirms that application of SSC may also support broader set of objectives, not only the business related.

All in all, successful operations of a SSC are rather focused on quality and even excellence of operations, not only the cost reduction. From the perspective of offshoring, implementing the model of a SSC does not require the establishment of a unit abroad, however then the cost arbitrage does not occur and access to skills is limited only to a home economy.

Many businesses face an issue that their expectations have not been fully met or the situation of an organisation deteriorated after introducing a SSC. There is even evidence that costs of operations have increased, while the performance suffered (Meijerink \& Bondarouk, 2013). The process of creating a SSC is a very complex organisational change project (Davis, 2005). He also focused on cost reduction and concluded that significant progress in this matter in firms has been achieved after a long period of trials and errors. Anyway, there is a significant gap in the research regarding the performance of SSCs and most of conclusions have been drawn from the limited number of observations or case studies. 
The expectations of delivering value may be hindered by misunderstanding the concept of SSC. It may be confused with central staff department (CSD). Strikwerda (2014) enlists multiple differences between those two, but the most important are:

- Orientation - SSC is business unit oriented, while CSD is headquarters oriented,

- Costs - SSC has budget based on demand, while CSD on corporate objectives and headquarters budgets,

- Location - SSC is optimally located with respect to inputs' costs and availability, while CSD is located at site of headquarters.

The problem is that the challenges to a SSC are arising simultaneously and mostly occur in the process of building the unit. Four main challenges are: power struggles, cost efficiency, survival in the long run, and leveraging knowledge (Knol, Jenssen, \& Sol, 2014). All of them are important, but the focus is on tensions between a SSC and business units, which should delegate some of their competences to the new unit designated to transform and implement those processes. This is frequently related to redundancies in the business units and an unwelcome approach towards a SSC. Such tensions increase when the SSC unit is being located abroad.

Critical findings regarding SSCs are not only important from the perspective of particular units. The complications in adaptation of the SSC model may also influence the performance of the entire ASB industries in host economies. The fact is also that the largest and most efficient organisations already deployed SSC units. It means that new units may be established by companies having less managerial experience or prerequisite resources, thus reducing the positive outcomes of the solution. From the perspective of host economies it may mean the reduction in the number of newly established units.

\subsection{Business process outsourcing}

Business process outsourcing (BPO) is a contractual relationship between a company moving its non-core business activities to an external service provider. If the external provider is located abroad, it is described as offshore business process outsourcing. Indeed, most relationships take the latter form and the notion business process outsourcing is also used to refer to foreign operations. Actually, BPO takes its most complex form when combined with offshoring. In such a case there is a possibility of double profits. Besides the potential gains from moving some processes outside a company, what can decrease costs and increase efficiency, we can also add gains stemmed from executing the activities in low cost locations and exploiting the economies of scale. When we analyse offshoring of ABS, the historical fact is that firms moved many processes to India, the Philippines or CEE in order to merely reduce costs. However, nowadays these locations provide a critical mass of knowledge, talents and organisational skills to execute large scale and knowledge-intensive processes for 
large international clients. It is well illustrated in the following statement. "The BPO industry is heterogeneous, differentiated by horizontal process domains such as HR, logistics, or finance, and vertical specializations such as medical transcription in the health sector and check processing and imaging in banking” (Mehta, Armenakis, Mehta, \& Irani, 2006, p. 326).

BPO should be viewed from a firm's perspective as strategic outsourcing and transformational outsourcing. The strategic outsourcing is defined as "the organizing arrangement that emerges when firms rely on intermediate markets to provide specialized capabilities that supplement existing capabilities deployed along firm's value chain” (Holcomb \& Hitt, 2007, pp. 466-467). The very important element of fast development of firms was the strategy of staff transfer to the clients' firms (Massini \& Miozzo, 2012). Thanks to such an approach the learning curve was very steep and integration into clients' organisations was facilitated. It means that frequently the entire departments have been outsourced. This is somehow similar to the process of creating own SSC, when workers have been transferred (at least to some extent) to the new unit. However due to the cost cutting approach the number of transferred employees could not be high.

Transformational outsourcing means employing an external provider experienced in bringing changes to the organisation (Chew \& Gottschalk, 2013). Such a transformation executed by an external management team may be performed faster and the internal resistance may be limited. It does not mean that each stakeholder will be satisfied with the results, anyway long-term goals may be achieved. The transformational outsourcing suits the issue of offshore ABS, as an organisation needs to change itself before the relocation of processes is possible.

The growth of BPO arrangements has important implications both for clients and vendors. Especially, when the client is from a developed economy and the vendor from an emerging one. The difference in the competences and capabilities can bring high value to both sides. The core areas of vendor firms, like management, employees and organisation may be impacted by the interaction with client firms (Brandl, Jensen, \& Lind, 2018).

The abundance of BPO providers, smaller and bigger, should increase the turnover rate and shorten the time span of contracts. However, especially in transactional services, offshore outsourcing arrangement are prone to be renewed (Manning, Lewin, \& Schuerch, 2011). It means that such arrangements are stable and offshore service providers are treated as long term partners, what helps both parties to increase investment in the cooperation.

Moreover, BPO has been considered as an integral part of a corporate strategy. Therefore, many firms opt to have only one strategic long-term provider of outsourced business services. Thanks to such an approach the transaction costs of negotiating with multiple partners many short-term contracts are avoided. Moreover, it is stressed that both sides need to invest time, money and efforts in establishing a successful cooperation network. 
In opposition to selecting one strategic partner, there is an option of having multiple vendors in various areas. Then the issue that arises is coordination of work, especially, when end-to-end processes are at stake. One of the advantages of multiple providers is the distribution of risk. Putting all data and processes in one vendor may be harmful and may lead to a certain level of a long-term dependence. Also when the issue is the security, a successful cyberattack on one unit means loss of lots of valuable data. Moreover, the distribution of risk may be also related to the need to geographically disperse the operations.

An additional advantage is gaining access to knowledge of many partners and not trusting that the one selected provider is the best long-term choice. This is the case, especially when we take into consideration the dynamic changes in technologies related to execution of business services. All in all, the strategy of having a few providers of business services is a challenging task due to the increased necessity for coordination.

There is an interplay between BPO and SSCs in strategies of enterprises. Both modes have been affected by the automation, however the outcomes for particular arrangements are far from being clear. According a consultancy, the captive offshoring is the thing of the past and outsourcing is something that will dominate future service deliveries (HfS Research, 2017). The example of such development may be a decision of an American engineering firm, Caterpillar, to move around 100 jobs from its financial centre in Northern Ireland to the outsourcing firm Accenture (Campbell, 2019). Important is that the outsourcing firm does not have any unit in Northern Ireland, so the jobs will be moved out of the region. It can be also interpreted that BPO further unbundles the core and support operations. SSCs have been pretty frequently created in proximity to existing manufacturing units, however in the case of BPO mode it is a very rare situation. On the other hand, another consultancy claims that companies plan to reduce the number of processes outsourced (Deloitte, 2019). BPO and SSC require different initial capabilities and can bring different results. When a company starts its own SSC, it is required to build a team that leads the new unit. The team is responsible for the transfer of processes to SSC. However, the drawback may be limited flexibility in comparison to BPO and the necessity to relay predominately on own knowledge of the organisation.

\subsection{Information technology outsourcing}

The necessity to identify a separate type of outsourcing units is related to the size of its market and different scope of operations comparing to BPO. IT services were pioneers when it comes to outsourcing, as many companies were not able to run IT operations on their own due to the sophistication of the activities. This type of services was technology-based. However, recently due to the evolution of many activities within companies, BPO is also highly technology-based. The rise of ITO can be dated in the end of 
1990s when Indian firms were employed to solve the "millennium bug" at Western firms' IT systems. Again we can combine outsourcing with offshoring.

Information technology outsourcing (ITO) means moving the IT processes to an external provider. More specifically ITO is defined "as the transfer of an organization's staff, IT infrastructure, processes, applications, and other IT-related activities to an external entity that possesses the capability to provide such service" (Pati \& Desai, 2005, p. 282). The role of ITO can be measured by its dynamics and size. ITO value in 1994 was estimated at $\$ 50$ billion, in 2000 it was already $\$ 152$ billion, and in 2014 - \$344 billion (Willcocks, Lacity, \& Sauer, 2017, p. 3).

It is postulated that ITO should be viewed from the strategic perspective of a firm, which can gain valuable knowledge to be used in the business value creation (Pati \& Desai, 2005). However, the evidence suggests that increased specificity of contracts and higher intensity of knowledge negatively influenced the longevity of outsourcing arrangements (Manning, Lewin, \& Schuerch, 2011). Such finding is somehow counterintuitive as the cost of investment in more complex processes is high and changing the partner requires a new round of negotiations and testing.

There is an ongoing evolution when it comes to ITO and offshoring of IT. "Early offshoring consisted of simple outsourcing contracts involving straight-forward simple tasks along the lines of call centres, help desks and simple software maintenance. Gradually, simple software maintenance became ever more sophisticated software development. As the education and sophistication level of foreign software developers increased, offshoring increased in volume and involved more sophisticated development. New technologies that increased bandwidth and the ability to offshore new and more complicated processes further increased the volume and sophistication of offshoring work" (Vedder \& Guynes, 2013, p. 133).

The recent trends regarding the proportions in allocation of financial resources towards an in-house IT department and offshoring processes in American firms indicate that till 2021 the values will roughly remain the same as they were in 2016 (Agrawal, Agrawal, Taylor, \& Seshadri, 2019). It means that companies are still interested in offshoring solutions, however they plan to keep a certain amount of the activities internally in order to deliver the support to end users or to develop proprietary solutions for their organisations.

\subsection{Research and development units}

The last category of ABS and frequently the smallest one, when it comes to headcount, are research and development (R\&D) units. They are also not that numerous as the other three types. However, due to their explicit knowledge creation they are crucial elements of MNEs' strategies. They are also very difficult to establish and gain expected results. It explains why, according to a study, shared services R\&D units are present only in 4\% of survey corporations (Deloitte, 2017, p. 7). 
If the main aim of establishing a SSC providing back or middle office services was cost arbitrage or scale of operation, the R\&D units are fundamentally focused on knowledge. The study of 1,722 R\&D projects confirmed that the wage difference, knowledge infrastructure difference, science and engineering talent pool size and political risk in host countries are main determining factors of choosing location for R\&D activities (Demirbag \& Glaister, 2010). The factors are similar to those deciding about any other knowledge-intensive offshoring, what helps to put the distinctive R\&D activities also in the context of offshoring. R\&D units could be described as SSCs for innovation. Indeed, in most cases the R\&D units are a result of the captive offshoring strategy. It is justified by the importance of R\&D and innovation within the strategies of firms. Moreover, the issue of confidentiality of operations within $R \& D$ units is the key.

Not all firms are capable of creating a R\&D unit abroad. The propensity of having offshore R\&D operations is rising with the size and productivity of a firm (Murphy \& Siedschlag, 2018). Recent studies provide evidence that the role of innovation offshoring in the overall level of innovation of firms has been decreasing (Rosenbusch, Gusenbauer, Hatak, Fink, \& Meyer, 2019). It can partly be explained by the spread of this strategy among firms, thus it is difficult to achieve unique results. However, another interpretation may be that firms engaged in offshoring innovative activities may actually decrease their internal innovative competences.

The offshoring of R\&D activities is a part of strategic competences of an enterprise. Therefore, R\&D is less likely to be offshored than for example production activities (Murphy \& Siedschlag, 2018). The same study confirms that, in general, the support activities are less frequently offshored than core activities. Anyway, the focus on R\&D is important as it can be translated into firms' behaviour of keeping a higher level of control over knowledge creation processes. Moreover, we should note that firms are aimed at retaining competences related to the R\&D functions and avoid conducting them abroad or by an external partner. This may partially explain why the R\&D units are not as numerous as other units providing business support services.

\subsection{Managing advanced business services units}

Very little attention has been paid to the issue of the specificity of managing offshore operations. The lack of interest of researchers may be explained by treating the offshore service units as a merely another type of a subsidiary. However, it is not the case. Frequently the position of ABS within the structures of a MNE has not been pronounced and has been kept quite low. Sometimes an ABS unit, even within the structures of a firm, has been treated as an external element. Such an approach to management of ABS units puts the entire organisation in disadvantage.

On the other hand, many organisations claim that after several years of development, their SSCs reached the level of fully-integrated units and they are treated as any other part of the core businesses. This is somehow associated with the fact, 
that ABS units have been created as a result of transferring tasks from many core units within an organisation.

In spite of the fact that the value added and the complexity of tasks is increasing, there is, in general, little progress in moving SSC upwards in the organisational hierarchy. This happens despite the fact that these units already control vast sources of knowledge and participate in creating new knowledge for the organisation. However, further centralisation of many more core operations may be against the interests of top management, as they would have to delegate most of their competences to SSCs. It also depends on the position of the head of a SSC within the structures of a company. There are companies, where this manager is a member of the top management team and has a direct access to the chief executive officer.

Many support units still focus on the cost reduction instead of delivering value to the entire organisation, what should be the future of ABS. They should not only execute simple tasks, but also restructure the organisation. This should change the direction of information and commands. The management of ABS units should not only accept tasks delegated by the headquarters, but should proactively build new competences to transform the entire organisations. In many ABS units there are functions related to transformation, however their role is mostly about incremental improvements of the existing processes, not profound changes of the organisation.

The approach of centralising transformation is important because of the technology behind many business processes. At the moment, the technology applied is more complex and its operations cannot be performed in a small scale by non-specialised units. Especially, when artificial intelligence is taken into consideration. Deploying the technology requires vast scale and human capital - the features of many SSCs. There must be a centralised unit with sufficient capacity to perform processes. Moreover, the centralisation is the key to automation of many tasks. Therefore, the concept of creating ABS units is fully justified. However, the issue is how to introduce the change to the entire organisation and boost performance of the ABS units.

Many ABS units are rather new establishments and they are still in the phase of increasing the scale, not efficiency. Frequently, the units are managed by people, who are effective managers, however they acquire many skills on the job. This is particularly the case for medium-level managers. The issue is that they frequently lack the broader perspective. It is partially linked to the role prescribed by the headquarters. The problems with SSCs is that the management of them may be blurred by the fact that they are surrounded by various principals (Boon, 2018). This leads to rising uncertainty related to the relations with particular stakeholders sometimes giving opposite orders or manifesting diversified expectations towards the SSC. On top of that, the power struggle significantly influences the efficiency of the unit and its possibility to leverage knowledge. The rivalry between different units within a MNE may be also seen in the context of coopetition, which merges cooperation and competition, and can lead to improvement of the business performance (Luo, 2005). 
The important element in the management of an ABS unit is a constant change, ability to adapt and acquire new skills. Therefore one of the biggest challenges is to manage the HR functions. Not surprisingly, in many hierarchies of ABS units, next to the general manager is the HR manager and administrative structures are organised around the two positions. Managing HR is one of the most important elements. This is both connected to recruiting good candidates, but also retaining them in very competitive job markets.

The issue that should be closely analysed by the management is the quality of services provided via offshoring. Before considering the quality, the distinction between services provided to internal and external clients should be raised, but also the issue of business clients (B2B) and individual customers (B2C). It is confirmed that the quality in provision of services via offshoring is more important that offshoring of physical objects due to, for example, dealing with the personal data (Thelen, Honeycutt Jr, \& Murphy, 2010). The same study confirms that there are perceived differences in quality when it comes the country of origin of services. This is important implications for managers planning their international provision of services. Managers should focus on providing services from locations adjusted to the expectations of the customers. It means that the price cannot be the only argument, however it frequently is. It means that when it comes to quality services, they should be provided from the location that is consider as trustworthy. This is a major challenge for voice services provided to the US from India or the Philippines.

This issue is also important in B2B arrangements. There have been frequent complains about cooperation with foreign providers of services (irrespective of internal or external nature). It means that the quality may be the main challenge in successful implementation of SSC or BPO model. It exacerbates the issue of the rivalry between services providers and business units. To avoid this, the proper communication and positioning of services providers is crucial. Managers cannot picture a SSC or BPO unit as a remote provider, but should rather decrease the distance to the core operations. Such solutions are important especially when the offshoring is considered as moving jobs from high to lower cost economies. This may result in the resistance in the source economies. 